\title{
The cooperation of pharmacologic-dose ascorbate with ceftriaxone against Staphylococcus aureus through bactericidal synergy and enhanced macrophage killing activity
}

\author{
Chulamartd Wirapakorn, ${ }^{1}$ Uthaibhorn Singkham-in, ${ }^{1}$ Sujittra Taratummarat, ${ }^{1}$ Saowapha Surawut, ${ }^{1}$ Peerapat Visitchanakun, \\ Tanittha Chatsuwan, ${ }^{2}$ Asada Leelahavanichkul ${ }^{2,3}$
}

Background: Ascorbate is a low-cost compound with a known bactericidal-synergy to antibitics. However, the synergy depends on concentrations and organisms. Thus, the synergy test by time-kill assay might be appropriate for the screening of the synergy.

Objective: We aimed to test the adjuvant property of ascorbate with ceftriaxone, a frequently prescribed $\beta$-lactam antibiotic.

Method: Ascorbate was tested with several bacteria from the American Type Culture Collection (ATCC) including Staphylococcus aureus, Pseudomonas aeruginosa, Acinetobacter baumannii and Escherichia coli for i) bactericidal property of ascorbate, alone or with ceftriaxone-combination, by time-kill assay, ii) an influence on the killing-activity of bone -marrow-derived macrophage and iii) the attenuation of myositis mouse model.

Result: The bactericidal synergy (determined with time-kill assay at $24 \mathrm{~h}$ ) against $S$. aureus, but not other selected bacteria, was demonstrated in ascorbate $(10$ and $40 \mathrm{mM})$ plus ceftriaxone at the minimal inhibitory concentration (1x MIC). Ascorbate alone, without antibiotic, enhanced macrophage killing-activity and directly eliminated bacteria at the concentration $10-40 \mathrm{mM}$ and $250 \mathrm{mM}$, respectively (both properties presented against $S$. aureus and P. aeruginosa, but not other bacteria). Ascorbate with ceftriaxone also reduced bacterial burdens in muscle and serum cytokines of $S$. aureus -myositis mouse model. Moreover, the synergy against the clinical isolated methicillin resistant S. aureus (MRSA) by time-kill assay and myositis model also presented.

Conclusion: Ascorbate-ceftriaxone synergy against S. aureus was demonstrated by time-kill assay and myositis model. Time-kill assy might be valuable as a screening test to select the patients that potentially benefit from ascorbate-ceftriaxone adjuvant therapy.

Key words: Bactericidal synergy; Ascorbate; Pharmacologic dose; S. aureus; Ceftrixone

\section{From:}

${ }^{1}$ Interdisciplinary Program of Medical Microbiology, Graduate school, Chulalongkorn University, Bangkok, Thailand

2 Department of Microbiology, Faculty of Medicine,

Chulalongkorn University, Bangkok, Thailand

${ }^{3}$ Center of Excellence in Immunology and Immune-mediated Diseases, Department of Microbiology, Faculty of Medicine, Bangkok, Thailand

\section{Background}

The influence of ascorbate (vitamin C), an essential vitamin for humans, in bacterial infection is firstly observed with the discovery that the incidence of bacterial pneumonia increases in patients with scurvy. ${ }^{1}$ The dose-dependent manner of ascorbate as an anti-/pro-oxidant, and its bactericidal properties are also presented. ${ }^{2,3}$ The bactericidal effect of ascorbate could be demonstrated at very high concentrations, but the indication
Corresponding author:

Asada Leelahavanichkul

Department of Microbiology, Faculty of Medicine;

Chulalongkorn University, Bangkok 104 30, Thailand

E-mail: aleelahavanit@gmail.com

for ascorbate administration against infectious diseases is still controversial. ${ }^{4-6}$ Indeed, several possible ascorbate bactericidal mechanisms are demonstrated including i) a direct effect on the bacterial cell wall, ii) an induction of oxidative substances, and iii) an improvement in neutrophil function. ${ }^{6-8}$ Although the essential role of intracellular ascorbate for the production of the reactive oxygen species (ROS) in activated neutrophils 
is well-known, ${ }^{9}$ the effectiveness of ascorbate-induced neutrophil bactericidal activity still depends on the organisms ${ }^{10}$ and ascorbate doses. ${ }^{11}$

As such, ascorbate at very high concentrations ( $\geq 16-32$ $\mathrm{mM}$ ) is necessary for the demonstration of its bactericidal property. ${ }^{10,12}$ Likewise, the adjuvant effect of high doses of ascorbate against several diseases have been reported including Mycobacterium tuberculosis, ${ }^{10}$ Candida albicans, and malignancy. ${ }^{13,14}$ Interestingly, ascorbate in pharmacologic concentrations (between 10 and $40 \mathrm{mM}$ ) is easily achievable through its continuous intravenous administration in patients. ${ }^{15}$ Despite the reported cases of ascorbate-induced oxalosis, ${ }^{16}$ no renal complications were demonstrated in a clinical study in patients ${ }^{15}$ and in mice, ${ }^{14}$ possibly due to the short course of administration. Because the concentration of ascorbate with bactericidal activity ${ }^{10,12}$ might be reduced by the proper antibiotic combination, we tested ascorbate in the achievable concentrations that were demonstrated in the patients. ${ }^{15}$

On the other hand, time-kill assay is the most appropriate method to determine the dynamic interaction between different antibiotics. This assay is frequently used to evaluate the synergism or antagonism of antibiotics in combination. ${ }^{17-19}$ The time-kill assay has been used to predict the effectiveness of combined antibiotics against resistant bacteria. ${ }^{20,21}$ As such, it is interesting to use the in vitro time-kill assay for the screening of ascorbate-antibiotic synergy in vivo. Moreover, the in vivo influence of ascorbate might be due to its immune modulation effect, because ascorbate is necessary for the activation of neutrophils. ${ }^{9}$ Hence, ascorbate possibly improves the function of macrophages because of the similar ROS-dependent killing activity between neutrophils and macrophages. Because the prevalence of Staphylococcus aureus, Pseudomonas aeruginosa, Acinetobacter baumannii, and Escherichia coli is high and the prescription of ceftriaxone, a broad spectrum $\beta$-lactam antibiotic, is common, we tested ascorbate-ceftriaxone synergy as a proof of concept experiment in vitro and in vivo.

\section{Method \\ Bacteria preparation}

Bacteria from the American Type Culture Collection (ATCC) including S. aureus (ATCC 25923), P. aeruginosa (ATCC 27853), A. baumannii (ATCC 19606), and E. coli (ATCC 25922) (ATCC, Manassas, VA, USA) were used. The minimal inhibitory concentrations (MICs) of ceftriaxone against these bacteria were $4,16,128$, and $4 \mu \mathrm{g} / \mathrm{mL}$, respectively. In addition, two clinically isolated strains of methicillin resistant $S$. aureus (MRSA) from patients in the intensive care unit were used to evaluate the possibility of the clinical translation. For MRSA identification, resistance to cefoxitin $(30 \mu \mathrm{g})$ was demonstrated by the production of an inhibition zone $\leq 21 \mathrm{~mm}$ in disc susceptibility testing.

\section{The time-kill assay}

The time-kill assay was performed followed a previous study.22 Ascorbate (Sigma-Aldrich, St. Louis, MO, USA) at $\mathrm{pH} 7.35$ in sterile water at different concentrations was used.
Ascorbate at 10 and $40 \mathrm{mM}$ concentrations were selected to test synergy, because these concentrations are achievable with continuous intravenous (iv) administration in patients. ${ }^{13,15}$ On the other hand, ascorbate concentrations more than 80 $\mathrm{mM}$ represent the hypothetical levels that might be associated with some in vivo complications. In the time-kill assay, each bacterial strain at $1 \times 10^{6} \mathrm{CFU} / \mathrm{mL}$ was incubated at $37^{\circ} \mathrm{C}$ with continuous shaking in several experimental groups including phosphate buffer solution (PBS) control, ascorbate, ceftriaxone (Sigma-Aldrich), and ceftriaxone plus ascorbate. In ceftriaxone alone and ceftriaxone plus ascorbate, ceftriaxone at $25 \%$ of the MIC (0.25x MIC) or at the MIC (1x MIC) against each bacterial strain was tested. Thus, different ceftriaxone concentrations were used for each bacterial strain due to the different MICs. Bacterial enumeration in colony forming units (CFUs) at $0,2,4,6,12$, and $24 \mathrm{~h}$ of the assay were determined by $24 \mathrm{~h}$ incubation on tryptic soy agar (TSA; Oxoid, Hampshire, UK) at $37^{\circ} \mathrm{C}$. The control of bacteria alone with neither ascorbate nor ceftriaxone was also performed. For MRSA, ceftriaxone at $512 \mu \mathrm{g} / \mathrm{mL}$ was used for the time-kill assay, because the MIC of ceftriaxone against both MRSA strains was higher than 512 $\mu \mathrm{g} / \mathrm{mL}$. Bactericidal synergy was defined as the lower bacterial count at $24 \mathrm{~h}$ of the time-kill assay of ceftriaxone plus ascorbate $(10$ or $40 \mathrm{mM})$ in comparison with ceftriaxone alone. All experiments were done in triplicate.

\section{Macrophage phagocytosis and killing activity}

The effect of ascorbate on macrophage function was tested due to the limited data on the topic in contrast to the wellknown influences of ascorbate on neutrophil function. ${ }^{23-26}$ The protocols of bone marrow (BM)-derived macrophage preparation $^{27}$ and macrophage phagocytosis ${ }^{28}$ were followed. In brief, bacteria were killed by heat at $56^{\circ} \mathrm{C}$ for $60 \mathrm{~min}$ and adjusted into $1 \times 10^{9}$ cells $/ \mathrm{mL}$ of PBS by the spectrophotometer (optical density at $600 \mathrm{~nm}$; OD600nm). After that, bacteria were labeled with $500 \mu \mathrm{g}$ of fluorescein isothiocyanate (FITC) (Sigma-Aldrich). Macrophages at $1 \times 10^{5}$ cells/well and heatkilled bacteria in the final ratios of macrophage to bacteria at 1:500 and 1:1000 in the final volume at $200 \mu \mathrm{L}$ were co -cultured with ascorbate (10 or $40 \mathrm{mM})$. Then, $0.2 \%$ trypan blue in PBS was used to quench the non-phagocytosed FITC -bacteria (extracellular FITC-bacteria) and the intracellular fluorescent intensity was measured at the excitation and emission wavelengths of $493 \mathrm{~nm}$ and $520 \mathrm{~nm}$. The intracellular fluorescent intensity represents the activity of macrophage phagocytosis. For macrophage killing activity, ${ }^{27}$ macrophages and live bacteria at the ratios of macrophage to bacteria at $1: 10^{5}$ with ascorbate $(10$ or $40 \mathrm{mM})$ was incubated at $37^{\circ} \mathrm{C}$ in a $5 \% \mathrm{CO}_{2}$ incubator for 15 minutes and washed with PBS. And then gentamicin (Sigma-Aldrich) at $100 \mu \mathrm{g} / \mathrm{mL}$ in DMEM was mixed for extracellular bacteria eradication. After that, the culture supernatant was removed and cell lysis was induced with lysis medium (distilled water with $0.01 \%$ bovine serum albumin). Subsequently, cell lysates in the serial dilutions were plated on TSA (Oxoid) for $24 \mathrm{~h}$ before bacterial enumeration. Macrophage killing activity is inversely correlated with the number of bacterial colonies. 


\section{Staphylococcal myositis mouse model}

Twelve-week-old male ICR mice purchased from the National Laboratory Animal Center, Nakornpathom, Thailand were used. The animal protocols were approved by the Faculty of Medicine at Chulalongkorn University following the $\mathrm{Na}$ tional Institute of Health (NIH) criteria, USA. S. aureus ATCC 25923 or the clinical strains of MRSA at $3 \times 10^{9} \mathrm{CFU}$ in $25 \mu \mathrm{L}$ of normal saline (NSS) were intramuscularly administered into the left upper thigh of mice. Two hours later, four different experimental groups ( $\mathrm{n}=8$ /group) were conducted including 1) ceftriaxone alone; intraperitoneal (ip) ceftriaxone $(10 \mathrm{mg} /$ $\mathrm{kg}$ in NSS) with subcutaneous (sc) NSS injection, 2) ascorbate alone; ip NSS with sc ascorbate ( $0.5 \mathrm{~g} / \mathrm{kg} /$ dose $), 3)$ ceftriaxone plus ascorbate; ip ceftriaxone plus sc ascorbate in the previous doses, and 4) NSS alone; NSS ip and sc. The volume per dose of ip and sc injection was $50 \mu \mathrm{L}$ and $125 \mu \mathrm{L}$, respectively. Then, ascorbate $(0.5 \mathrm{~g} / \mathrm{kg} /$ dose $)$ or NSS at $125 \mu \mathrm{L}$ was subcutaneously administered above the lesion every $2 \mathrm{~h}$ for three more injections. A subtherapeutic dose of ceftriaxone $(10 \mathrm{mg} / \mathrm{kg})$ was selected instead of the recommended dose $(50 \mathrm{mg} / \mathrm{kg}$ ) to determine synergy easier. Because of the rapid renal excretion of ascorbate after iv injection, ${ }^{14}$ the frequent sc injection of ascorbate was used to maintain ascorbate levels in the myositis mouse model. ${ }^{29}$

All mice were sacrificed with blood collection through cardiac puncture under isoflurane anesthesia $2 \mathrm{~h}$ after the last ascorbate injection (10 h after bacterial injection). Serum cytokines (TNF- $\alpha$, IL-6, and IL-10) and serum ascorbate were
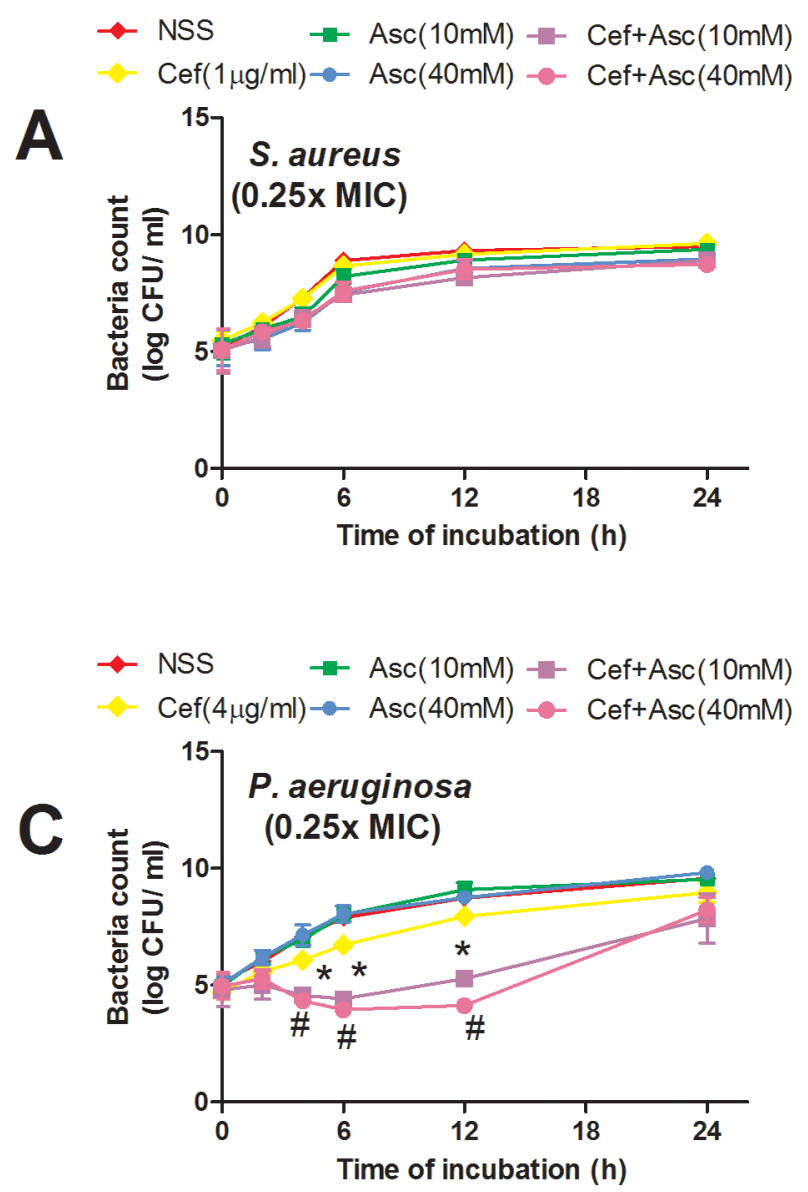

Figure 1. analyzed by ELISA assays (eBioscience, San Diego, CA, USA) and ascorbic acid assays (BioAssay U.S. Biological, Salem, MA, USA), respectively. In addition, $100 \mathrm{mg}$ of muscle at the inoculation site was homogenized in PBS then plated onto TSA (Oxoid) for bacterial colony enumeration as previously prescribed. The in vivo bactericidal synergy was defined as the lower bacterial burden in muscle at sacrifice in ceftriaxone plus ascorbate in comparison with ceftriaxone treatment alone.

\section{Statistical analysis}

Mean \pm SE was used for data presentation and the differences between groups were determined by one-way analysis of variance (ANOVA) with Tukey's comparison test. Repeated measures by ANOVA with Bonferroni post hoc analysis were used for the analysis of the data with several time-points. $P$ values $<0.05$ were considered statistically significant. SPSS 11.5 software (SPSS Inc., Chicago, IL, USA) was used for all statistical analyses.

\section{Results}

Ascorbate bactericidal synergy by time-kill assay and macrophage killing activity

Time-kill assay was performed to test the in vitro synergy. Ascorbate alone at 10 and $40 \mathrm{mM}$ was not effective for bacterial neutralization (Figure 1). Ascorbate with ceftriaxone at $0.25 \mathrm{x}$ MIC reduced bacterial burdens at 3 through $12 \mathrm{~h}$ of incubation only in $P$. aeruginosa, but not other bacterial strains, in comparison with ceftriaxone alone (Figure 1 Left column).
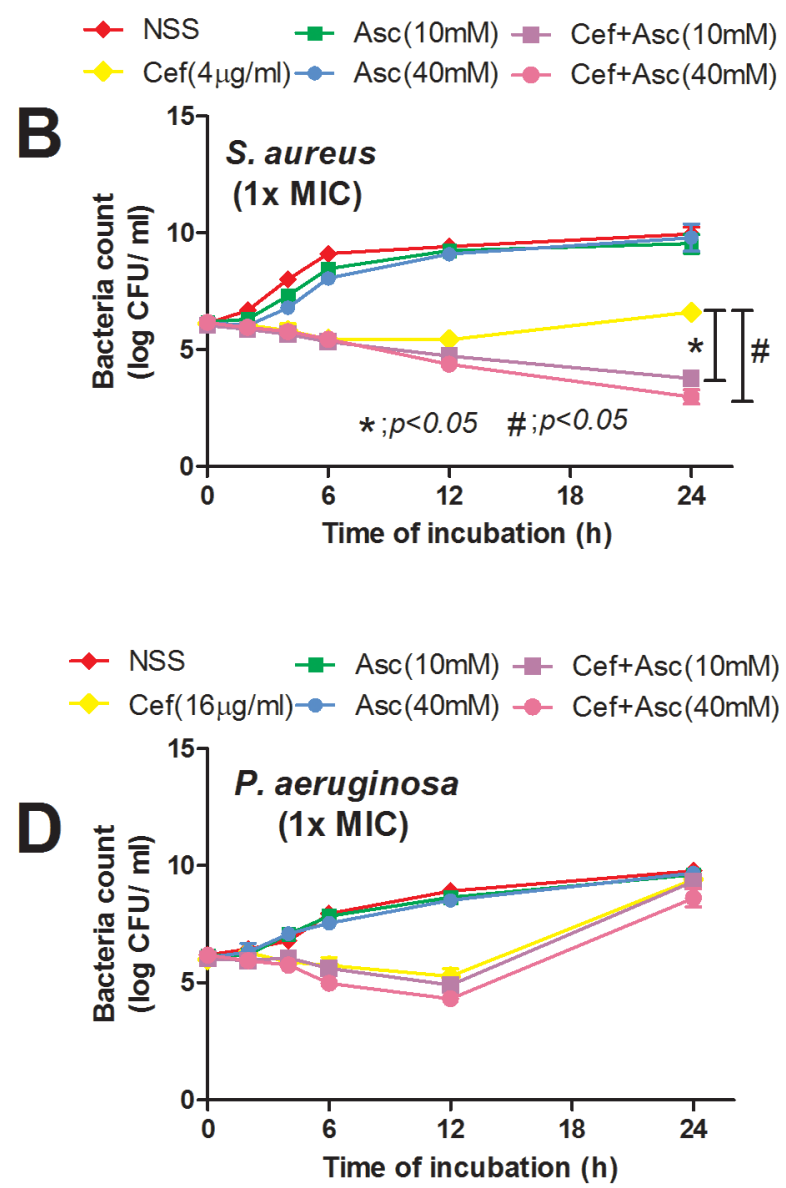

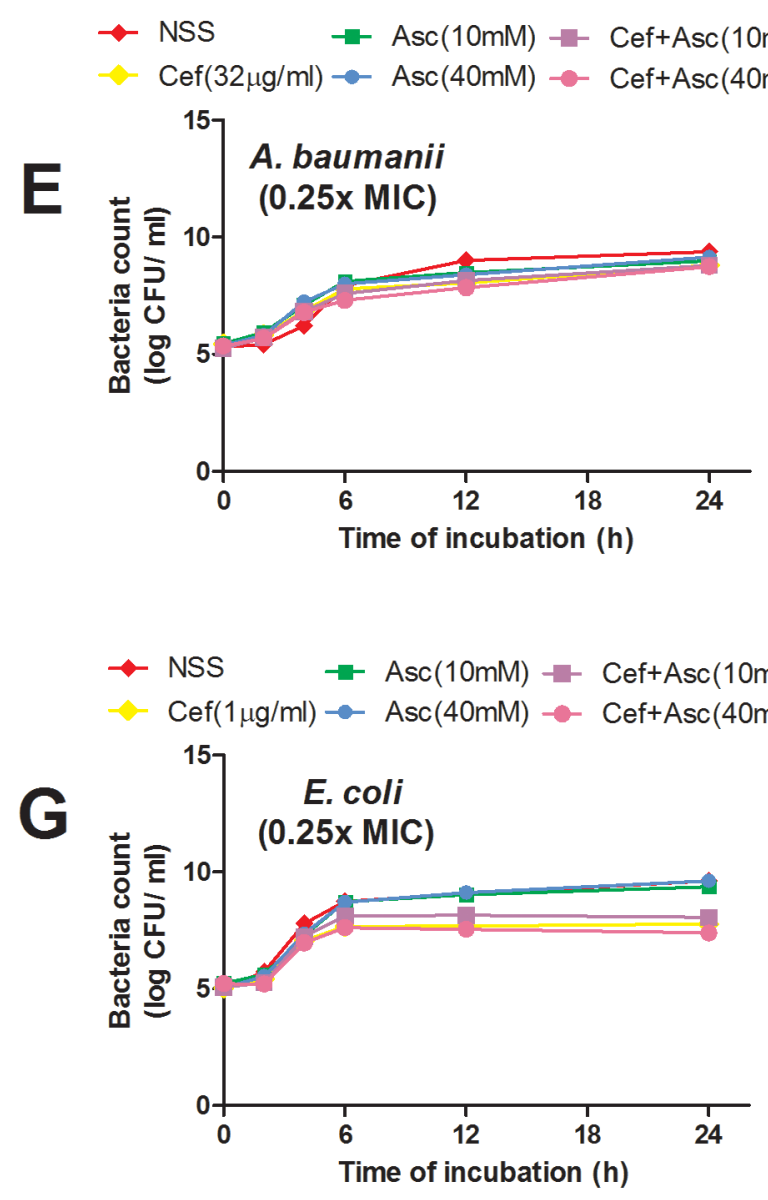

Figure 1. (Continued)

The transient adjuvant effect of ascorbate in ceftriaxone against $P$. aeruginosa might be due to ascorbate degradation after $12 \mathrm{~h}$ of incubation; however, the addition of fresh ascorbate at $12 \mathrm{~h}$ could not reduce bacterial burdens at $24 \mathrm{~h}$ (data not shown). On the other hand, in comparison with ceftriaxone alone, ascorbate with ceftriaxone at $1 \mathrm{x}$ MIC reduced $S$. aureus burdens, but not other bacteria, at $24 \mathrm{~h}$ of incubation (Figure 1 Right column). Because bactericidal synergy was defined as the low bacterial count at $24 \mathrm{~h}$ of the time-kill assay, but not the transient bacterial reduction in the earlier time-points, the only demonstrable ascorbate-ceftriaxone synergy was against $S$. aureus.

In addition, the direct bactericidal effect of ascorbate against $S$. aureus and $P$. aeruginosa, but not toward other bacteria, was demonstrated with ascorbate at $80 \mathrm{mM}$ and $250 \mathrm{mM}$, respectively (Figure 2). With $250 \mathrm{mM}$ ascorbate, bactericidal effect against $S$. aureus and $P$. aeruginosa could be demonstrated as early as $3 \mathrm{~h}$ and at $24 \mathrm{~h}$ of incubation, respectively (Figure 2A and $2 \mathrm{~B}$ ). These data suggested that the bacterial susceptibility to ascorbate was organism specific.

Moreover, the influences of ascorbate on macrophage function were explored. Ascorbate did not enhance macrophage bacterial phagocytosis against all of the selected ATCC bacteria (data not shown), which was different from the improved neutrophil phagocytosis in several reports..$^{14,23,30,31}$ However, ascorbate improved macrophage killing activity against all selected bacteria, except for A. baumannii (Figure 3). While
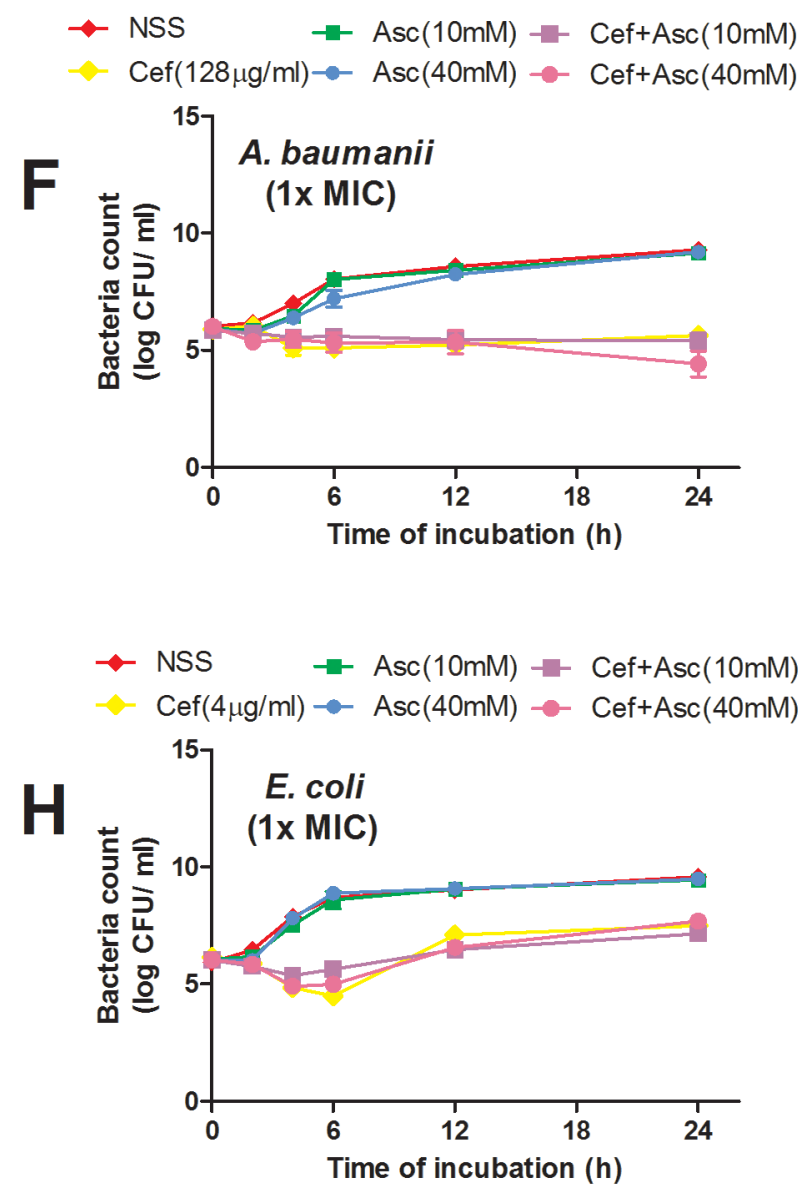

macrophage killing activity against both $S$. aureus and $P$. aeruginosa were demonstrated only with ascorbate $40 \mathrm{mM}$, the killing activity against $E$. coli with ascorbate $10 \mathrm{mM}$ was better than with $40 \mathrm{mM}$ (Figure 3).

\section{Ascorbate bactericidal synergy against a staphylococcal myo- sitis mouse model}

A staphylococcal myositis mouse model was performed to test the in vivo synergy. Because bacterial neutralization depends on ascorbate concentrations, serum ascorbate after sc injection was measured. As such, serum ascorbate between 10 and $40 \mathrm{mM}$ was achievable within $1.5 \mathrm{~h}$ after a single sc injection, and ip ceftriaxone did not alter the ascorbate level (Figure 4A). Because the duration that ascorbate levels were more than $10 \mathrm{mM}$ was only $1.5 \mathrm{~h}$ after a single sc injection, we then performed sc injection above the bacterial injection site every $2 \mathrm{~h}$ for a total of four doses. The mouse samples were collected $2 \mathrm{~h}$ after the last ascorbate injection. Ceftriaxone plus ascorbate showed the lowest bacterial burdens in muscle and serum cytokines (TNF- $\alpha$, IL-6, and IL-10) (Figure 4B-4E). Because of the subtherapeutic dose of ceftriaxone, ceftriaxone treatment alone showed a tendency toward the reduction in bacterial burdens compared with non-antibiotic groups but did not reach statistically significant levels (Figure 4B).

To more closely resemble the clinical situation, clinical isolates of MRSA were used. Ascorbate-ceftriaxone synergy was demonstrated with ascorbate at $10 \mathrm{mM}$ and $40 \mathrm{mM}$ in strain \#1, 

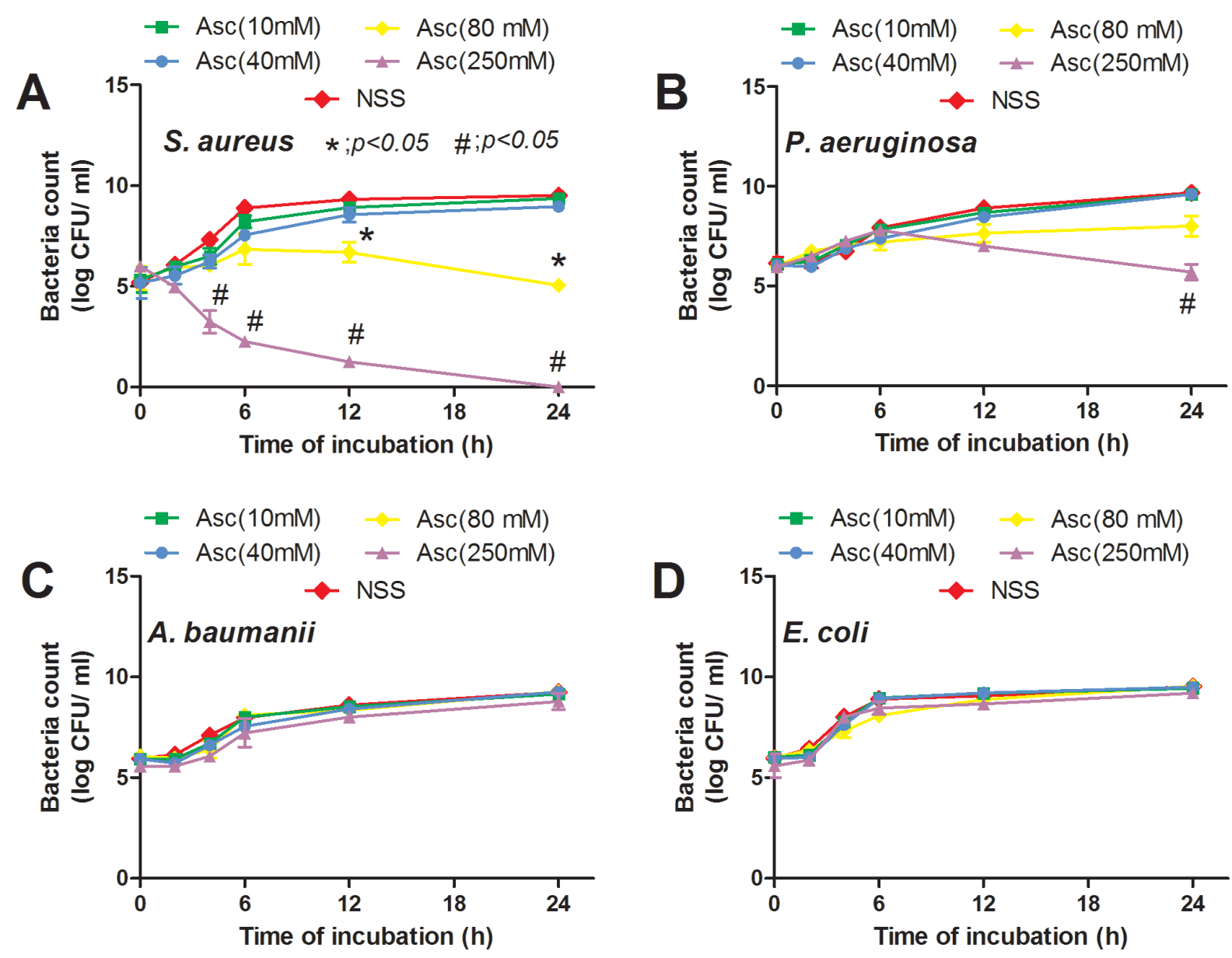

Figure 2.
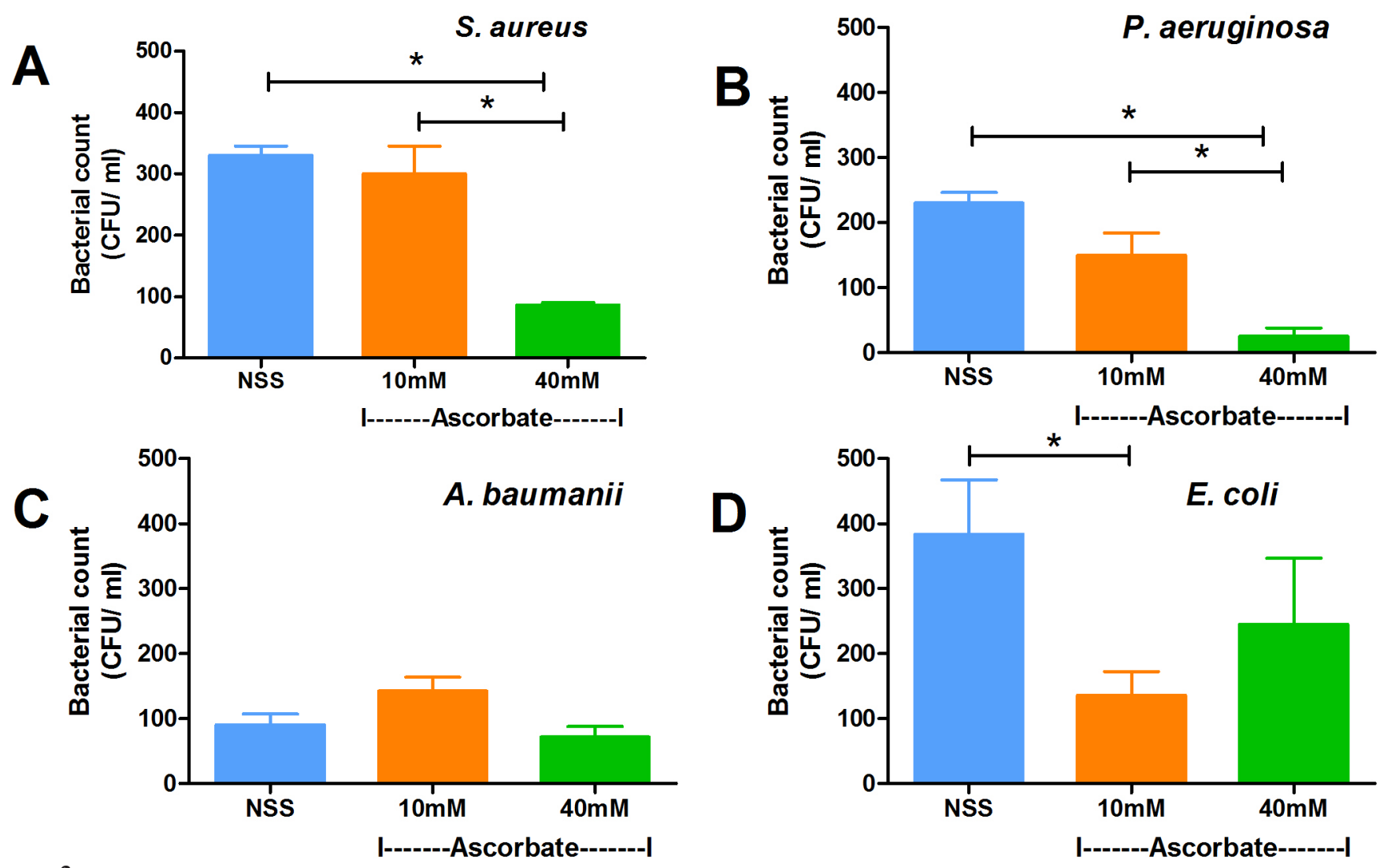

Figure 3. 

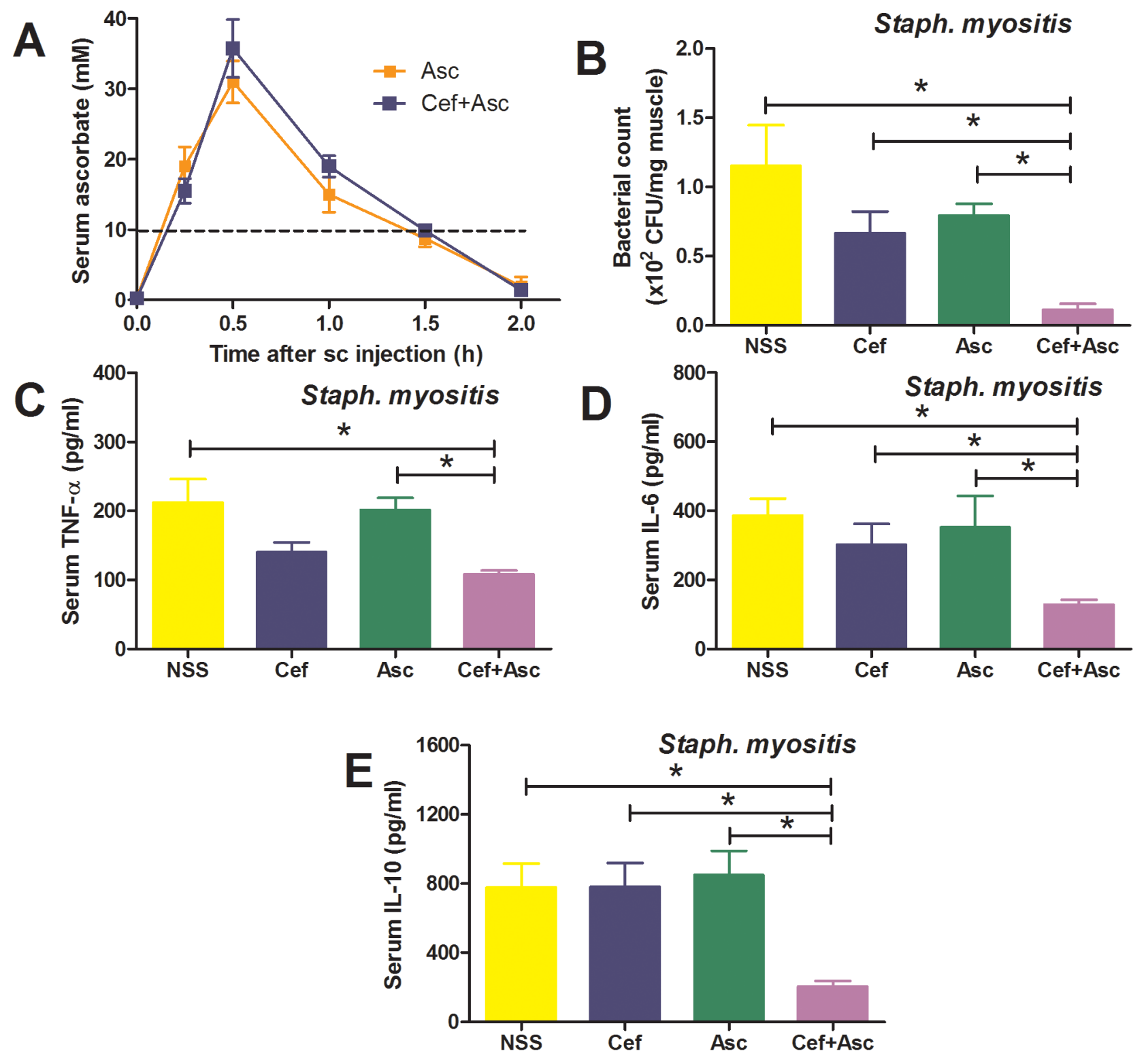

Figure 4.
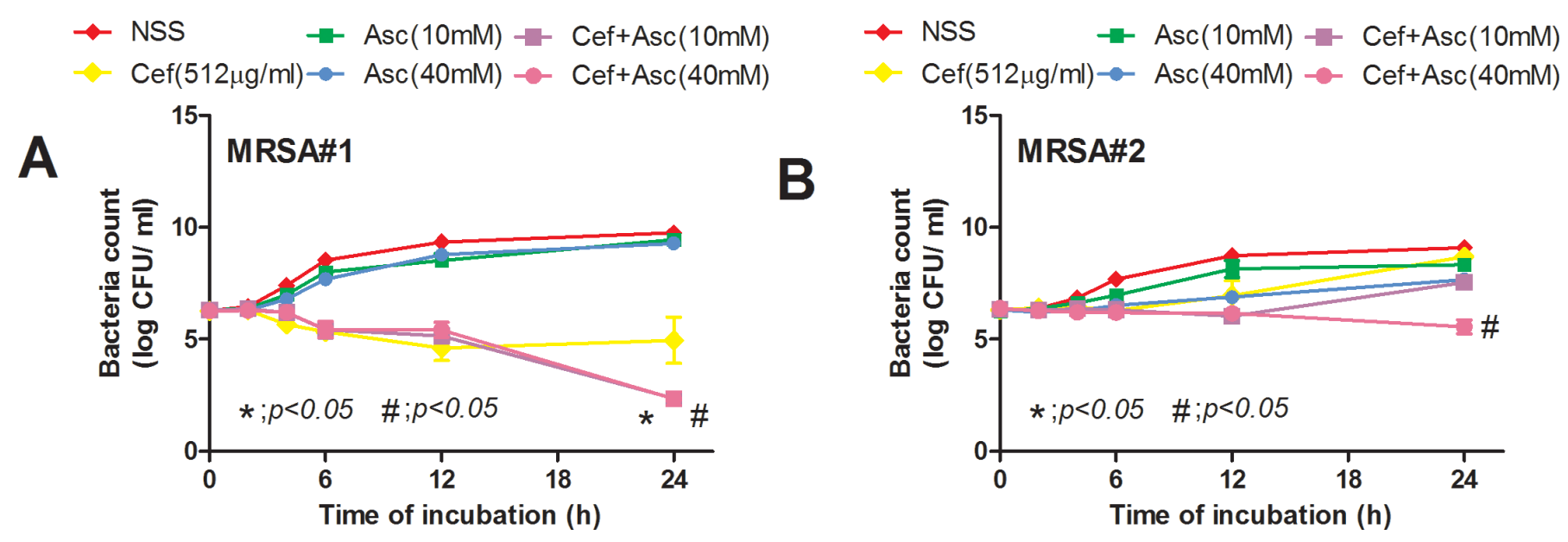

Figure 5. 

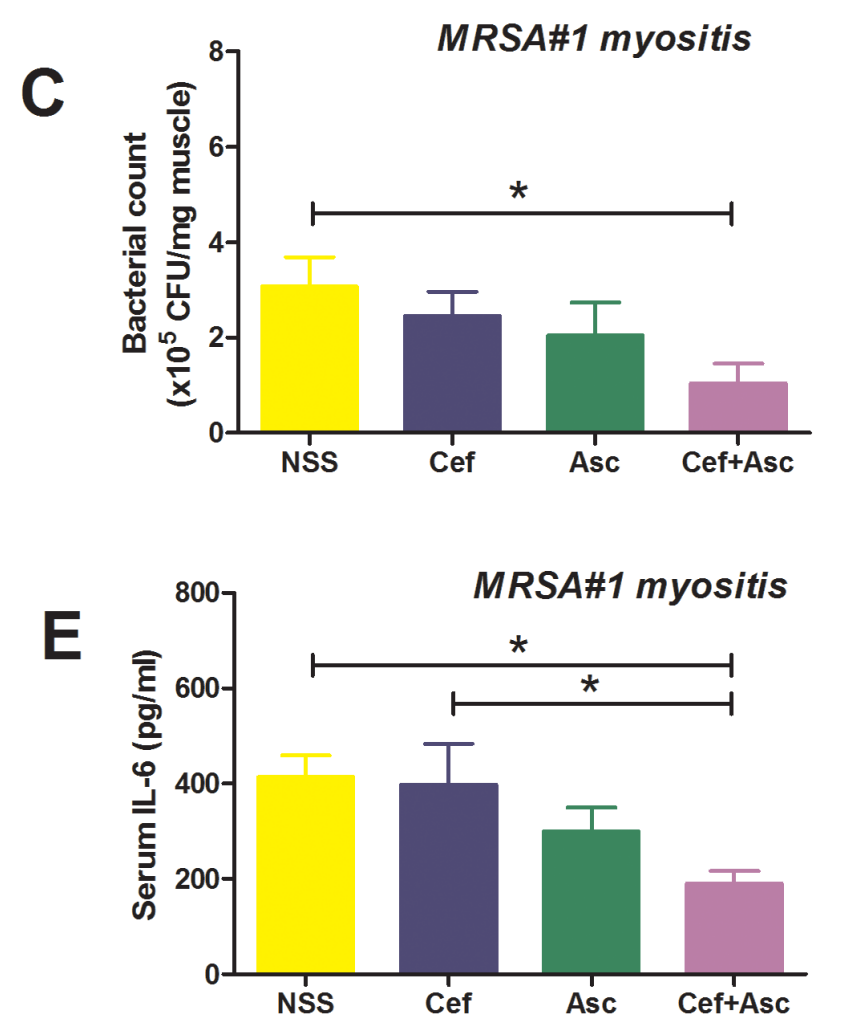

Figure 5. (Continued)

and synergy presented only with ascorbate $40 \mathrm{mM}$ in strain \#2, as determined by the time-kill assay at $24 \mathrm{~h}$ (Figure 5A and 5B). However, the in vivo bactericidal synergy as demonstrated by the lower bacterial burdens in muscle with ascorbate-ceftriaxone in comparison with ceftriaxone alone could be found only in MRSA strain \#1 but not strain \#2 (Figure 5C-5F).

\section{Discussion}

Ascorbate is low-cost, widely available, and the adjunctive administration of ascorbate with an antibiotic might be a beneficial strategy, especially in situations with limited resources. ${ }^{32}$ Thus, as a proof of concept experiment, we explored in vitro synergy with the time-kill assay and tested in vivo synergy with a myositis mouse model.

Although ascorbate is a potent anti-oxidant, ascorbate in the concentration $>0.2 \mathrm{mM}$ shows pro-oxidant properties. ${ }^{7,13,14}$ After oral administration, ascorbate concentrations in blood are lower than $0.2 \mathrm{mM}$ due to intestinal transporter saturation. ${ }^{18}$ The injection route is necessary to induce higher ascorbate blood levels, and bactericidal property was demonstrated at the level $>16 \mathrm{mM} .^{10,12}$ However, the concentration might be lower with the appropriate antibiotic combination. While the bactericidal property of ascorbate was demonstrated with ascorbate alone between $80 \mathrm{mM}$ and $250 \mathrm{mM}$ in the time-kill assay, the bactericidal effect of ascorbate could be found between $10 \mathrm{mM}$ and $40 \mathrm{mM}$ in combination with an antibiotic. And ascorbate between $10 \mathrm{mM}$ and $40 \mathrm{mM}$ could be easily achieveable in patients with the continuous iv injection without serious complications. ${ }^{15}$ However, an appropriate level of antibiotic is necessary as ascorbate-ceftriaxone synergy against $S$. aureus was demonstrated only with ceftriaxone at $1 \mathrm{x}$
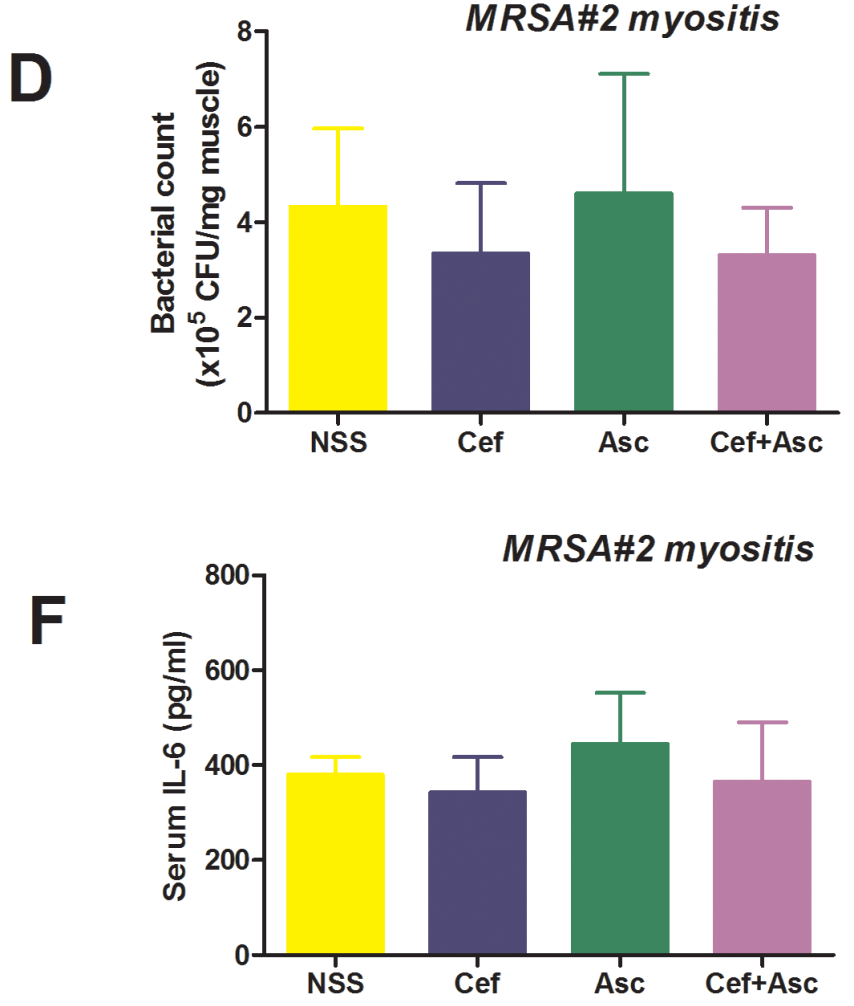

MIC but not at $0.25 \mathrm{x}$ MIC. Moreover, the synergy was only working against the specific bacteria, as ascorbate-ceftriaxone reduced $P$. aeruginosa at 3 through $12 \mathrm{~h}$ after incubation but not at $24 \mathrm{~h}$. This implied a possible ascorbate neutralization mechanism by $P$. aeruginosa. Hence, in vitro ascorbate-ceftriaxone synergy depends on i) concentrations of antibiotics and ascorbate and ii) the microorganisms. More studies are needed to explore the mechanisms of the synergy.

In addition, ascorbate-ceftriaxone synergy was also demonstrated in vivo with a staphylococcal myositis model. Hence, the in vivo synergy might be responsible for the synergistic bactericidal property together with the improved activity of immune cells. Likewise, the intracellular ascorbate concentration is 100 -fold higher after macrophage activation and this might affect the killing activity. ${ }^{35}$ Another possible mechanism of in vivo ascorbate-antibiotic synergy is enhanced extracellular $\mathrm{H}_{2} \mathrm{O}_{2}$ production; however, this process might be neutralized during an acute infection. ${ }^{33,34}$ Finally, ascorbate -ceftriaxone synergy was tested against two clinical strains of MRSA as a proof of principle in antibiotic resistant strains of bacteria.

The synergy in the myositis model could be demonstrated only with strain $\# 1$, which the synergy was demonstrated with ascorbate at $10 \mathrm{mM}$ and $40 \mathrm{mM}$ by time-kill assay. In contrast, the synergy in the myositis model could not be demonstrated in strain \#2, which the synergy was demonstrated only with ascorbate $40 \mathrm{mM}$ by time-kill assay. Hence, the time-kill assay with ascorbate might be appropriate for the screening test of the clinical outcomes. However, only two strains of MRSA were tested in this study, and more intensive studies of MRSA will be necessary. Moreover, other methods to test synergy, 
such as checkerboard analysis, might also be appropriate tests. More studies on the correlation of the in vitro analysis to the in vivo outcomes are in need.

Finally, several limitations should be mentioned. First, other antibiotics might be different from ceftriaxone for the demonstration of ascorbate bactericidal synergy. Second, the in vivo synergy against gram-negative bacteria was not tested, because a gram-negative bacterial challenge could not produce myositis (data not shown). Third, the synergy demonstrated here depends on local activity and not systemic administration.

In conclusion, a proof of concept study to use ascorbate as an adjunctive therapy to antibiotics against bacterial infection was demonstrated. This synergy might be beneficial in situations with limited resources. In the real clinical situation, ascorbate monitoring in serum and antibiotic concentrations might improve the efficacy of synergy. With more intensive studies, ascorbate-antibiotic synergy might be an alternative choice against antibiotic resistant bacteria, but more studies are warranted.

\section{Acknowledgments}

AL worked under the Center of Excellence in Immunology and Immune-Mediated Diseases, Department of Microbiology, Faculty of Medicine. This study was supported by Thailand Government Fund (RSA-6080023)

\section{References}

1. Hemila H. Vitamin C and Infections. Nutrients. 2017;9(4).

2. Podmore ID, Griffiths HR, Herbert KE, Mistry N, Mistry P, Lunec J. Vitamin C exhibits pro-oxidant properties. Nature. 1998;392(6676):559.

3. Levine M, Padayatty SJ, Espey MG. Vitamin C: A Concentration-Function Approach Yields Pharmacology and Therapeutic Discoveries. Adv Nutr. 2011;2(2):78-88.

4. Besra GS, Morehouse CB, Rittner CM, Waechter CJ, Brennan PJ. Biosynthesis of mycobacterial lipoarabinomannan. J Biol Chem. 1997;272 (29):18460-6.

5. Eddy BP, Ingram M. Interactions between ascorbic acid and bacteria. Bacteriol Rev. 1953;17(2):93-107.

6. Rawal BD. Bactericidal Action of Ascorbic Acid on Pseudomonas aeruginosa: Alteration of Cell Surface as a Possible Mechanism. Chemotherapy. 1978;24(3):166-71

7. Chen Q, Espey MG, Krishna MC, Mitchell JB, Corpe CP, Buettner GR, et al. Pharmacologic ascorbic acid concentrations selectively kill cancer cells: action as a pro-drug to deliver hydrogen peroxide to tissues. Proc Natl Acad Sci U S A. 2005;102(38):13604-9.

8. Chatterjee M, Saluja R, Kumar V, Jyoti A, Kumar Jain G, Kumar Barthwal $\mathrm{M}$, et al. Ascorbate sustains neutrophil NOS expression, catalysis, and oxidative burst. Free Radic Biol Med. 2008;45(8):1084-93.

9. Wang Y, Russo TA, Kwon O, Chanock S, Rumsey SC, Levine M. Ascorbate recycling in human neutrophils: induction by bacteria. Proc Natl Acad Sci U S A. 1997;94(25):13816-9.

10. Vilcheze C, Hartman T, Weinrick B, Jacobs WR Jr. Mycobacterium tuberculosis is extraordinarily sensitive to killing by a vitamin C-induced Fenton reaction. Nat Commun. 2013;4:1881.

11. Wilson JX, Wu F. Vitamin C in sepsis. Subcell Biochem. 2012;56:67-83.

12. Zhang HM, Wakisaka N, Maeda O, Yamamoto T. Vitamin C inhibits the growth of a bacterial risk factor for gastric carcinoma: Helicobacter pylori. Cancer. 1997;80(10):1897-903.

13. Chen Q, Espey MG, Sun AY, Pooput C, Kirk KL, Krishna MC, et al. Pharmacologic doses of ascorbate act as a prooxidant and decrease growth of aggressive tumor xenografts in mice. Proc Natl Acad Sci USA. 2008;105(32):11105-9.
14. Leelahavanichkul A, Somparn P, Bootprapan T, Tu H, Tangtanatakul P, Nuengjumnong R, et al. High-dose ascorbate with low-dose amphotericin $\mathrm{B}$ attenuates severity of disease in a model of the reappearance of candidemia during sepsis in the mouse. Am J Physiol Regul Integr Comp Physiol. 2015;309(3):R223-34.

15. Hoffer LJ, Levine M, Assouline S, Melnychuk D, Padayatty SJ, Rosadiuk K, et al. Phase I clinical trial of i.v. ascorbic acid in advanced malignancy. Ann Oncol. 2008;19(11):1969-74.

16. Massey LK, Liebman M, Kynast-Gales SA. Ascorbate increases human oxaluria and kidney stone risk. J Nutr. 2005;135(7):1673-7.

17. White RL, Burgess DS, Manduru M, Bosso JA. Comparison of three different in vitro methods of detecting synergy: time-kill, checkerboard, and E test. Antimicrob Agents Chemother. 1996;40(8):1914-8.

18. Pfaller MA, Sheehan DJ, Rex JH. Determination of fungicidal activities against yeasts and molds: lessons learned from bactericidal testing and the need for standardization. Clin Microbiol Rev. 2004;17(2):268-80.

19. Balouiri M, Bouhdid S, Sadiki M, Ouedrhiri W, Barkai H, El Farricha $\mathrm{O}$, et al. Effect of preconditioning cobalt and nickel based dental alloys with Bacillus sp. extract on their surface physicochemical properties and theoretical prediction of Candida albicans adhesion. Mater Sci Eng C Mater Biol Appl. 2017;71:111-7.

20. Peck KR, Kim MJ, Choi JY, Kim HS, Kang CI, Cho YK, et al. In vitro time-kill studies of antimicrobial agents against blood isolates of imipenem-resistant Acinetobacter baumannii, including colistin- or tigecycline-resistant isolates. J Med Microbiol. 2012;61(Pt 3):353-60.

21. Foerster S, Unemo M, Hathaway LJ, Low N, Althaus CL. Time-kill curve analysis and pharmacodynamic modelling for in vitro evaluation of antimicrobials against Neisseria gonorrhoeae. BMC Microbiol. 2016;16:216.

22. Treyaprasert W, Schmidt S, Rand KH, Suvanakoot U, Derendorf H. Pharmacokinetic/pharmacodynamic modeling of in vitro activity of azithromycin against four different bacterial strains. Int J Antimicrob Agents. 2007;29(3):263-70.

23. Bozonet SM, Carr AC, Pullar JM, Vissers MC. Enhanced human neutrophil vitamin $\mathrm{C}$ status, chemotaxis and oxidant generation following dietary supplementation with vitamin C-rich SunGold kiwifruit. Nutrients. 2015;7(4):2574-88.

24. Washko PW, Wang Y, Levine $M$. Ascorbic acid recycling in human neutrophils. J Biol Chem. 1993;268(21):15531-5.

25. Weiss WP, Hogan JS. Effects of dietary vitamin $C$ on neutrophil function and responses to intramammary infusion of lipopolysaccharide in periparturient dairy cows. J Dairy Sci. 2007;90(2):731-9.

26. Elste V, Troesch B, Eggersdorfer M, Weber P. Emerging Evidence on Neutrophil Motility Supporting Its Usefulness to Define Vitamin C Intake Requirements. Nutrients. 2017;9(5)

27. Surawut S, Ondee T, Taratummarat S, Palaga T, Pisitkun P, Chindamporn A, et al. The role of macrophages in the susceptibility of Fc gamma receptor IIb deficient mice to Cryptococcus neoformans. Sci Rep. 2017;7:40006.

28. Miliukiené VV, Biziulevičiené GJ, Chaustova LP, Pilinkiené AV, Biziulevičius GA. Determination of quantitative parameters of Escherichia coli phagocytosis by mouse peritoneal macrophages. Cell Tiss Biol. 2007; 1(5):446-50.

29. Oztas E, Kilic A, Ozyurt M, Korkmaz A, Basustaoglu A. Effect of hyperbaric oxygen and penicillin in a murine model of streptococcal myositis. Undersea Hyperb Med. 2001;28(4):181-6.

30. Anderson R. Effects of ascorbate on leucocytes: Part II. Effects of ascorbic acid and calcium and sodium ascorbate on neutrophil phagocytosis and post-phagocytic metabolic activity. S Afr Med J. 1979;56(10):401-4.

31. Anderson R. Ascorbate-mediated stimulation of neutrophil motility and lymphocyte transformation by inhibition of the peroxidase/ $\mathrm{H} 2 \mathrm{O} 2 /$ halide system in vitro and in vivo. Am J Clin Nutr. 1981;34(9):1906-11.

32. Ventola CL. The antibiotic resistance crisis: part 1: causes and threats. P T. 2015;40(4):277-83.

33. Mojic M, Bogdanovic Pristov J, Maksimovic-Ivanic D, Jones DR, Stanic M, Mijatovic S, et al. Extracellular iron diminishes anticancer effects of vitamin C: an in vitro study. Sci Rep. 2014;4:5955.

34. Brosnahan MM, Erb HN, Perkins GA, Divers TJ, Borges AS, Osterrieder N. Serum iron parameters and acute experimental EHV-1 infection in horses. J Vet Intern Med. 2012;26(5):1232-5.

35. May JM, Huang J, Qu ZC. Macrophage uptake and recycling of ascorbic acid: response to activation by lipopolysaccharide. Free Radic Biol Med. 2005;39(11):1449-59. 